\title{
Permanent pacemaker insertion following transcatheter aortic valve replacement: Not infrequent, not benign, and becoming predictable
}

\author{
Craig M. Jarrett, MD, MBA
}

\author{
From the Division of Cardiac Surgery, Brigham and Women's Hospital, Boston, Mass. \\ Disclosures: Author has nothing to disclose with regard to commercial support. \\ Received for publication Dec 4, 2016; accepted for publication Dec 7, 2016; available ahead of print Jan 25, 2017. \\ Address for reprints: Craig M. Jarrett, MD, MBA, Division of Cardiac Surgery, Brigham and Women's Hospital, \\ 75 Francis St, Boston, MA 02115 (E-mail: cjarrett@partners.org). \\ J Thorac Cardiovasc Surg 2017;153:1063-4 \\ 0022-5223/\$36.00 \\ Copyright (C) 2016 by The American Association for Thoracic Surgery \\ http://dx.doi.org/10.1016/j.jtcvs.2016.12.014
}

Al-Azzam and colleagues ${ }^{1}$ share their transcatheter aortic valve replacement (TAVR) experience to better understand the factors associated with permanent pacemaker insertion (PPI) following TAVR. In a retrospective review of 300 patients, $19.7 \%$ of patients had PPI within 30 days of TAVR. The authors found insertion of a self-expanding prosthesis and presence of a baseline right bundle branch block (RBBB) were predictive of PPI, whereas aortic valve oversize and calcium score were not.

Prior work suggests a host of factors predictive of PPI following TAVR. These include aortic valve calcium score, landing zone calcification, ${ }^{2}$ left ventricular outflow tract (LVOT) calcium volume in the area below the left coronary cusp $\left(\mathrm{LVOT}_{\mathrm{LC}}\right)$ and right coronary cusp $\left(\mathrm{LVOT}_{\mathrm{RC}}\right){ }^{3} \mathrm{im}-$ plantation depth, ${ }^{3,4}$ porcelain aorta, ${ }^{5}$ aortic valve oversize, ${ }^{6}$ use of self-expanding valve, ${ }^{7,8}$ baseline $\mathrm{RBBB},{ }^{3,6,8-11}$ baseline left bundle branch block, male gender, ${ }^{12}$ and left ventricular end-diastolic diameter, ${ }^{6}$ to name a few. Taking each factor individually, the current weight of evidence suggests insertion of a self-expanding valve and baseline $\mathrm{RBBB}$ are most consistent in predicting the need for PPI following TAVR. Al-Azzam and colleagues' findings corroborate both in their single-center study. ${ }^{1}$

Other factors gaining traction as predictors of PPI following TAVR include LVOT $_{\mathrm{LC}}$ and $\mathrm{LVOT}_{\mathrm{RC}}$ calcium volume and implantation depth. ${ }^{3,4}$ Aortic valve calcium score was not predictive of PPI in this study, but as the authors suggest, aortic valve calcium score is likely too generalized of a measurement. LVOT $_{\mathrm{LC}}$ and $\mathrm{LVOT}_{\mathrm{RC}}$ calcium volume are better determinants of calcification specific to the membranous septum and atrioventricular conduction system. Like greater calcium volume, greater implantation depth of the prosthesis lower in the LVOT might increase the mechanical stress on the conduction system leading to higher rates of conduction disturbances. There is growing evidence that $\mathrm{LVOT}_{\mathrm{LC}}$ and $\mathrm{LVOT}_{\mathrm{RC}}$ calcium volume and implantation depth are predictive of PPI following TAVR, but these were not addressed in this study.

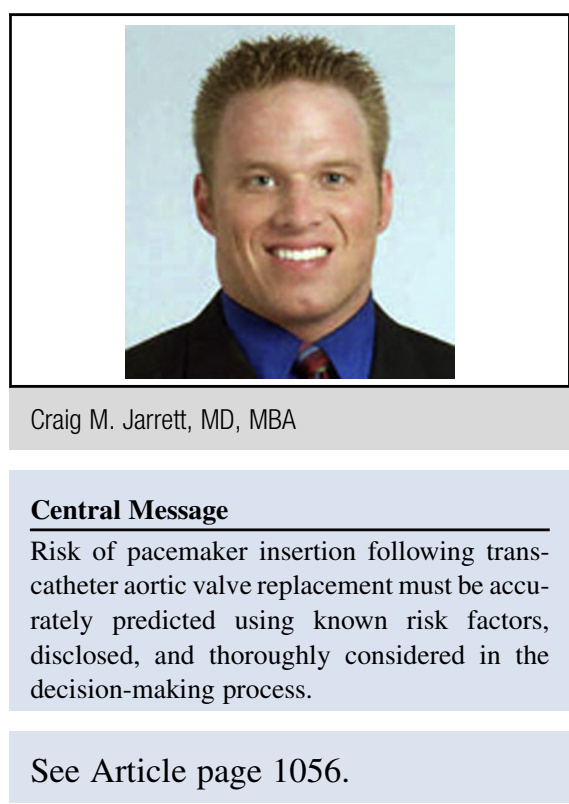

PPI following TAVR occurs frequently with rates as high as 1 in 3 patients in some series, whereas rates following surgical aortic valve replacement are lower. ${ }^{5,13-15}$ Furthermore, PPI following TAVR is not benign. It is associated with increased cost, a longer duration of hospitalization, and higher rates of repeat hospitalization and mortality or repeat hospitalization at 1 year. ${ }^{6}$ In patients who are high risk for surgical aortic valve replacement, these risks are a reasonable price to pay. As TAVR becomes more common in patients with intermediate and even low risk for surgical aortic valve replacement, these risks may be too high. Determining the proper balance will require careful risk assessment and further investigation.

With continued improvements in both TAVR valve design and experience, it is conceivable in the near future a majority of aortic valve replacements will be performed using a transcatheter approach. When comparing TAVR with the current gold standard of surgical aortic valve replacement, it is essential to predict the risks and benefits of TAVR as completely and accurately as possible, especially because TAVR expands into low- and intermediate-risk patient populations. For the reasons noted above, this includes the risk of PPM and its consequences. Work, such as this by Al-Azzam and colleagues, ${ }^{1}$ helps to better predict the true risks of TAVR. On the basis of these and others' results, preprocedural decision making, consultation, and informed consent for TAVR 
should include and document an increased risk of PPM implantation in those patients undergoing TAVR with selfexpanding prosthesis and with known RBBB.

\section{References}

1. Al-Azzam F, Greason KL, Krittanawong C, Williamson EE, McLeod CJ, King KS, et al. The influence of native aortic valve calcium and transcatheter valve oversize on the need for pacemaker implantation after transcatheter aortic valve insertion. J Thorac Cardiovasac Surg. 2017;153:1056-62.

2. Latsios G, Gerckens U, Buellesfeld L, Mueller R, John D, Yuecel S, et al. "Device landing zone" calcification, assessed by MSCT, as a predictive factor for pacemaker implantation after TAVI. Catheter Cardiovasc Interv. 2010;76:431-9.

3. Mauri V, Reimann A, Stern D, Scherner M, Kuhn E, Rudolph V, et al. Predictors of permanent pacemaker implantation after transcatheter aortic valve replacement with the SAPIEN 3. JACC Cardiovasc Interv. 2016;9:2200-9.

4. Urena M, Mok M, Serra V, Dumont E, Nombela-Franco L, DeLarochelliere R, et al. Predictive factors and long-term clinical consequences of persistent left bundle branch block following transcatheter aortic valve implantation with a balloon-expandable valve. J Am Coll Cardiol. 2012;60:1743-52.

5. Ledwoch J, Franke J, Gerckens U, Kuck KH, Linke A, Nickenig G, et al. Incidence and predictors of permanent pacemaker implantation following transcatheter aortic valve implantation: analysis from the German transcatheter aortic valve interventions registry. Catheter Cardiovasc Interv. 2013;82:E569-77.

6. Nazif TM, Dizon JM, Hahn RT, Xu K, Babaliaros V, Douglas PS, et al. Predictors and clinical outcomes of permanent pacemaker implantation after transcatheter aortic valve replacement: the PARTNER (Placement of AoRtic TraNscathetER Valves) trial and registry. JACC Cardiovasc Interv. 2015;8(1 Pt A):60-9.

7. Abdel-Wahab M, Mehilli J, Frerker C, Neumann FJ, Kurz T, Tolg R, et al. Comparison of balloon-expandable vs self-expandable valves in patients un- dergoing transcatheter aortic valve replacement: the CHOICE randomized clinical trial. JAMA. 2014;311:1503-14.

8. Agarwal S, Parashar A, Kumbhani DJ, Svensson LG, Krishnaswamy A, Tuzcu EM, et al. Comparative meta-analysis of balloon-expandable and selfexpandable valves for transcatheter aortic valve replacement. Int J Cardiol. 2015; 197:87-97.

9. Bagur R, Rodes-Cabau J, Gurvitch R, Dumont E, Velianou JL, Manazzoni J, et al. Need for permanent pacemaker as a complication of transcatheter aortic valve implantation and surgical aortic valve replacement in elderly patients with severe aortic stenosis and similar baseline electrocardiographic findings. JACC Cardiovasc Interv. 2012;5:540-51.

10. Koos R, Mahnken AH, Aktug O, Dohmen G, Autschbach R, Marx N, et al. Electrocardiographic and imaging predictors for permanent pacemaker requirement after transcatheter aortic valve implantation. J Heart Valve Dis. 2011;20:83-90.

11. Ramazzina C, Knecht S, Jeger R, Kaiser C, Schaer B, Osswald S, et al. Pacemaker implantation and need for ventricular pacing during follow-up after transcatheter aortic valve implantation. Pacing Clin Electrophysiol. 2014;37: $1592-601$.

12. Siontis GC, Juni P, Pilgrim T, Stortecky S, Bullesfeld L, Meier B, et al. Predictors of permanent pacemaker implantation in patients with severe aortic stenosis undergoing TAVR: a meta-analysis. J Am Coll Cardiol. 2014;64:129-40.

13. Adams DH, Popma JJ, Reardon MJ, Yakubov SJ, Coselli JS, Deeb GM, et al. Transcatheter aortic-valve replacement with a self-expanding prosthesis. $N$ Engl J Med. 2014;370:1790-8.

14. Leon MB, Smith CR, Mack MJ, Makkar RR, Svensson LG, Kodali SK, et al. Transcatheter or surgical aortic-valve replacement in intermediate-risk patients. N Engl J Med. 2016;374:1609-20.

15. Smith CR, Leon MB, Mack MJ, Miller DC, Moses JW, Svensson LG, et al. Transcatheter versus surgical aortic-valve replacement in high-risk patients. $N$ Engl J Med. 2011;364:2187-98. 